\title{
Primary Care Practice-Based Research Networks: Working at the Interface Between Research and Quality Improvement
}

James W. Mold, MD, MPH ${ }^{1}$

Kevin A. Peterson, MD, MPH ${ }^{2}$

${ }^{1}$ Department of Family and Preventive Medicine, University of Oklahoma Health Sciences Center, Oklahoma City, Okla

${ }^{2}$ Department of Family and Community Medicine, University of Minnesota, Minneapolis, Minn
Conflicts of interest: none reported

\section{CORRESPONDING AUTHOR}

James W. Mold, MD, MPH

University of Oklahoma Health Sciences Center

Department of Family and Preventive

Medicine

900 NE 10th St

Oklahoma City, OK 73104

james-mold@ouhsc.edu

\begin{abstract}
PURPOSE We wanted to describe the emerging role of primary care practicebased in research, quality improvement (QI), and translation of research into practice (TRIP).

METHODS We gathered information from the published literature, discussions with PBRN leaders, case examples, and our own personal experience to describe a role for PBRNs that comfortably bridges the gap between research and QI, discovery and application, academicians and practitioners - a role that may lead to the establishment of true learning communities. We provide specific recommendations for network directors, network clinicians, and other potential stakeholders.
\end{abstract}

RESULTS PBRNs function at the interface between research and QI, an interface called TRIP by some members of the research community. In doing so, PBRNs are helping to clarify the difficulty of applying study findings to everyday care as an inappropriate disconnect between discovery and implementation, research and practice. Participatory models are emerging in which stakeholders agree on their goals; apply their collective knowledge, skills, and resources to accomplish these goals; and use research and QI methods when appropriate.

CONCLUSIONS PBRNs appear to be evolving from clinical laboratories into learning communities, proving grounds for generalizable solutions to clinical problems, and engines for improvement of primary care delivery systems.

Ann Fam Med 2005;3(Suppl 1):S12-S20. DOI: 10.1370/afm.303.

\section{INTRODUCTION}

$\mathrm{P}$ rimary care practice-based research networks (PBRNs) are challenging traditional distinctions between research and quality improvement $(\mathrm{QI})$, emphasizing the importance of linking discovery and application, research and practice. These networks are finding that less translation is required to apply research to practice when clinicians are involved in deciding what to study, how to study it, and how to evaluate and present the results. Yet integration of research and practice is not easy because it often requires new kinds of relationships, conceptual frameworks, and even languages for clinicians, patients, researchers, academic institutions, and funding agencies

In this article, we discuss these challenges and the various ways in which PBRNs are addressing them. We then propose that PBRNs are gradually evolving from clinical laboratories into collaborative learning communities that use both traditional and nontraditional methods to identify, disseminate, and integrate new knowledge to improve primary care processes and patient outcomes. The information on which we base our observations and conclusions was derived from publications, presentations, and informal conversations with individuals working in PBRNs in the United 
States. Most of these networks are made up of small to moderate-sized, mixed-payer practices, however, we believe that the principles ought to apply to larger practices and managed health care systems as well.

\section{THE INTERSECTION OF RESEARCH AND QI}

In medicine at least, research and QI have been considered fundamentally different activities. Research is defined as "a systematic search for facts,"1 whereas medical QI is defined as "an interdisciplinary process designed to raise the standards of the delivery of preventive, diagnostic, therapeutic, and rehabilitative measures in order to maintain, restore, and improve health outcomes of individuals and populations." ${ }^{2}$ The primary emphasis of research is thus on discovery, and the primary emphasis of QI is on application. Some other distinctions have been made between research and QI in the medical and nursing literature (Table 1). . $^{3 \cdot 15}$

Academicians often approach research as if it were a goal. They speak about the importance of doing research as opposed to using research methods to answer a question or solve a problem to improve outcomes. This approach is understandable because success in academia is generally measured by numbers of grants, publications, and presentations, not by improved clinical processes or population health. The focus of primary care clinicians, on the other hand, is on outcomes. They are interested in solutions to everyday challenges, and their experience with research suggests that it rarely provides such solutions. The questions that are addressed in studies too often seem reductionistic, esoteric, uninteresting, and disconnected from the realities of patient care. Results may take years to become available for everyday use.

Successful PBRNs have recognized that, for researchers and clinicians to choose to work together for an extended period of time, they must focus on outcomes that are relevant to clinical practice, that is, solutions to the challenges that clinicians and their patients face on a frequent basis. Not surprisingly, the methods required include both discovery (research) and application (QI). In the corporate world, this combination is called research and development. The key question for a new or emerging PBRN to ask is, "What can we accomplish more effectively or efficiently by working together in a practice-based network?"

Organizations involved in QI have discovered the benefits of extending their work beyond individual practices. Although these QI organizations still assess individual clinician or practice performance, they also compare performance across clinicians and practices, creating performance benchmarks. Within the bounds of confidentiality, they use these benchmarks to motivate practices or to create competition, and they share the information they have learned from more successful practices with less successful ones. ${ }^{16-20}$

Many QI organizations are also using a method pioneered by the Institute for Healthcare Improvement called Breakthrough Series Collaboratives. ${ }^{21-32}$ Collaboratives generally include 10 to 20 unrelated clinical practice teams working both independently and collaboratively for a period of 6 to 8 months to improve performance in a predetermined area (eg, management of patients with diabetes). Under the guidance of local and national experts, team members study, test, and implement the latest available knowledge to produce rapid improvements in performance. The rapid cycle method of QI-Plan-Do-Study-Act_-is taught and encouraged. Individual successes and failures (the discovery component) are shared via listservs and during periodic conference calls and meetings, and improvement guides (the application component) are developed and disseminated based on lessons learned within the collaborative and from other collaboratives. Clearly, these activities include both discovery and application, research and QI.

Several PBRNs (eg, the Oklahoma Physicians Resource/ Research Network [OKPRN], the 
Minnesota Academy of Family Physicians Research Network [MAFPRN], and the Kentucky Ambulatory Network (KAN) have established collaborative relationships with QI organizations, and other PBRNs and PBRN practices have become involved in Breakthrough Series Collaboratives. Still other PBRNs have combined the concepts and methods of research and QI in other ways.

\section{Example: The Colorado}

\section{Ambulatory Research Network}

The Colorado Ambulatory Research Network (CaReNet) and the affiliated High Plains Research Network improve practice by routinely capturing and analyzing patient safety errors. Error patterns are compared with statewide malpractice claims data and presented to a clinical steering committee, which identifies areas of greatest concern or opportunity for improvement. Through direct observation in participating practices, practice research coordinators (PRCs) construct maps of the relevant processes. Each practice then appoints members to a learning group made up of representatives from all parts of the practices. These learning groups analyze and discuss the errors data and the process maps, and develop theories and strategies called practice process improvement reports. Researchers and PRCs then turn these reports into planned intervention and evaluation cycles. Their discoveries and successful interventions are presented at national meetings and published in peer-reviewed journals. ${ }^{33}$

\section{Recommendations}

\section{For Network Directors}

- When talking with academic colleagues or preparing grant applications, use the term researcb instead of the term quality improvement. When talking with clinicians, however, note that in most cases "research" is not a very useful word.

- Work collaboratively with clinician members to solve problems and achieve objectives that immediately improve practice or help patients. Use traditional research methods when appropriate to achieve those ends, and use other methods when they work better than traditional ones.

- Look for opportunities to develop relationships with QI organizations and other organizations interested in improving primary care practice and patient outcomes.

\section{For PBRN Clinician Members}

- Do not let the academicians take over your network. Insist on a strategic plan that makes sense to you and your patients.

- Make sure that the work is not just about getting grants and publishing papers. Insist that the results be framed so that they are clinically useful.

\section{TRANSLATION OF RESEARCH INTO PRACTICE}

There has been increasing concern in the last few years about the failure of research findings to rapidly affect clinical practice. ${ }^{34-41}$ This failure has highlighted the difficulties clinicians encounter when trying to implement new approaches in their practices and the relative ineffectiveness of traditional methods such as continuing medical education and journal publications for disseminating new medical information. ${ }^{42-50}$ Using the results of a number of published studies, Balas and Boren ${ }^{51}$ estimated that it takes an average of 17 years to turn $14 \%$ of original research findings into changes in care that benefit patients.

Clinicians have responded that much of the new knowledge published in journals is not directly applicable to practice. They also point out that clinical practice is complex, and that even potentially relevant research findings must be adapted to fit fiscal realities, individual practice styles and configurations, and unique patient populations and communities. ${ }^{52-54}$ These concerns have led to a perceived need for more relevant research and for better ways to translate research into practice (TRIP). ${ }^{55}$

Primary care PBRNs are well positioned to accomplish both because they include parties on both sides of the translational gap, researchers and clinicians. In fact, PBRNs are not only addressing these issues, they are also reframing them. For example, an assumption of TRIP is that research flows from the bench (laboratory) to the clinic, an assumption challenged by members of PBRNs, who suggest that it is as important to put practice into research as it is to put research into practice. In theory, when clinicians are involved in decisions regarding what to study, how to study it, and how to analyze and frame the data, they are more likely to find the results to be both useful and usable. Research carried out in practice settings should be more relevant and generalizable. When clinicians actually participate in a research project, furthermore, they are probably more likely to use the results. To the extent that this phenomenon is due to the Hawthorne effect, it would be viewed as contamination in classical research, but in practice-based research, it is viewed as a benefit.

The National Institutes of Health and the Agency for Healthcare Research and Quality are now funding research that informs the translational process. ${ }^{56-58}$ Their question seems to be, "How can we get physicians to do the things that we know, from previous research, work?" PBRNs are certainly participating in this effort, but they are finding the question to be more complicated. For example, practice guidelines and quality standards, based on research, rarely take into account comorbidities, financial barriers, and patient 
priorities, and very few of them have been adequately field-tested. Information is also emerging about the complexities of primary care practices and the lack of appropriate systems and resources necessary to make meaningful changes. Implementation of new research findings often requires major changes in office systems, including changes in staffing and staff responsibilities, and patient scheduling and flow patterns, as well as installation of new technologies, which can often only be accomplished with outside assistance.

\section{Example: Improving Diabetes Care by Primary Care Translation}

MAFPRN has been using technology to help drive research into sustainable clinical practice. The IMPACT study is a randomized controlled trial of a highly developed, multifaceted diabetes intervention in 24 primary care clinics. The intervention begins by evaluating the organizational structures of primary care offices and identifying existing barriers. A set of 9 intervention components is then introduced to correct existing deficiencies at each clinic. Key features include targeting of high-risk patients, a patient reminder system for routine visits, both generic and patient-specific physician reminders, a diabetes registry, a networked reporting system, and physician education. Implementation of the intervention is facilitated by a local diabetes intervention team assisted by a site coordinator and a local physician champion.

\section{Recommendations}

\section{For Network Directors}

- Do not hesitate to question basic assumptions about translation and the generation and flow of information. Consider doing research that challenges these assumptions, and that both clarifies and reduces the gaps between research and practice.

- Encourage and support attendance by clinicians at national research meetings, and advocate for inclusion of clinicians on review panels and as peer reviewers for journals.

\section{For PBRN Clinician Members}

- Insist that clinicians play a major role in setting the agenda for PBRN activities, in planning specific projects, and in deciding how to frame and disseminate the results.

- Seize opportunities that arise to attend national research meetings or to serve on review boards or as a peer reviewer for a journal.

\section{PARTICIPATORY RESEARCH IN PBRNS}

In an effort to address TRIP, numerous PBRNs have tried to involve clinicians in as many steps of the research process as possible. A diagram constructed at a primary care methods conference in 2000 illustrates this concept (Figure 1). Some PBRNs (eg, the University of California, San Francisco-Stanford Research Network and OKPRN) have developed research training programs for clinicians to enhance their ability to participate in all phases of the research process.

When a multidisciplinary group can focus on common goals, however, it is not usually necessary or desirable for everyone to participate in every step. The term community-based participatory research has been used to describe research conducted collaboratively with and within communities, in which the goals are improved community-based outcomes, and all phases of the project are approved by a committee that includes stakeholders and methodologists. ${ }^{59-64}$ The principles of this research approach can be found in a position paper endorsed by the North American Primary Care Research Group. ${ }^{65}$ The key features are a strong foundation of understanding, respect, and trust among the participating entities; a set of mutually agreed-upon goals; and a governance structure and rules of conduct that ensure that the process will remain collaborative from goal generation to implementation and dissemination of results.

The community-based participatory research model seems well suited to PBRNs, in which the "community" could include clinicians, their office staff, their patients, various local health-related organizations, or combinations thereof. Major obstacles to progress in this area have been the time and funding required to establish and maintain the foundational relationships. In a par-

\section{Figure 1. Diagram of practice-based research involving clinicians in research steps.}

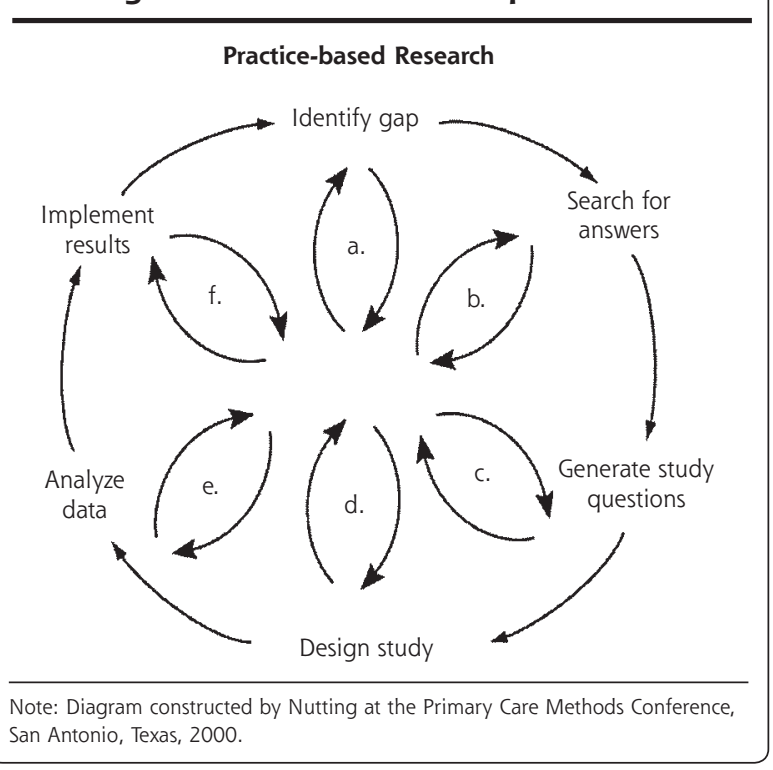


ticipatory process, all participants contribute to and gain from the process, but the focus is always on the community as a whole. This approach requires a major attitudinal shift for many academicians, because in this model, researchers contribute methodologic expertise but generally have less influence over the goals than do other partners, and implementation of the results takes precedence over publications and academic accolades, although the latter are an important by-product.

\section{Example: The Dartmouth-Northern New England Primary Care Cooperative Research Network}

During a New England blizzard 20 years ago, a heated debate took place among clinicians from the Dartmouth-Northern New England Primary Care Cooperative Research Network (the COOP). The topic: do doctors really know what matters to their patients? As a result of that discussion, the clinicians carried out a study subsequently published in the Journal of the American Medical Association in 1983. ${ }^{66}$ The findings showed that, in fact, doctors and nurses are frequently unaware of what matters most to their patients.

For more than 30 years, the COOP has functioned as a voluntary network of independent primary care clinicians in New Hampshire, Maine, and Vermont. Clinician members meet regularly to advise the COOP staff, prioritize research activities, and determine organizational policies. Many of the COOP's members are in small towns and rural areas that lack a large clinician community or opportunities to discuss clinical innovations and other subjects of interest to physicians and nurses. As a forum for intellectual exchange, the COOP has enabled clinicians to serve as sources of information for each other, which has affected clinical practice.

Over the years, the COOP has also successfully competed for millions of dollars in grants from the National Institutes of Health and private foundations, and has published more than 50 peer-reviewed articles, all focused on increasing the ability of clinicians to understand and respond to patient needs and concerns. As a result of its 1983 study, the COOP membership elected a governing board of practicing clinicians to provide guidance to the Dartmouth Medical School's Department of Community and Family Medicine. During the past 5 years, the COOP has also worked closely with the Institute for Healthcare Improvement to improve interactions between patients and clinicians.

\section{Recommendations}

\section{For Network Directors}

- Read about community-based participatory research, and consider adapting the principles within your PBRN.
- Develop an organizational structure that includes all relevant stakeholders, and a process that focuses on common goals and objectives.

- Recognize and make optimal use of the skills and resources of all participants.

\section{For PBRN Clinician Members}

- Recognize that although academicians have certain important skills and resources, these assets are insufficient. Your skills and resources and those of other potential partners are at least as important to the success of the network and its work.

\section{PBRNS AS PROVING GROUNDS}

Some have proposed that professional associations should encourage all of their members to become involved in PBRNs to accelerate the process of discovery and dissemination of new information. Others have advocated limiting membership in PBRNs to highly committed clinicians who are willing to invest extra time and effort to discover and test ways to improve care, relying on traditional strategies (eg, publications and presentations) and affiliations with other organizations (eg, QI organizations, state health departments, professional associations) to disseminate the results

Some QI organizations view the networks as proving grounds-sources of good ideas and effective solutions to important clinical and administrative challenges. The QI organizations help fund these efforts and then disseminate the findings. Similar relationships have been developed with other governmental and private organizations. For example, a state department of health has collaborated with a PBRN to develop ways to encourage greater use of its immunization registry. The method will be developed and tested in the network before its dissemination throughout the rest of the state. A private software development company might establish a contractual relationship with a PBRN to learn what clinicians need, then develop and test products in the network, hoping to eventually sell them outside of the network. The network could then earn a small share of the profits.

\section{Example: The Practice Partner Research Network}

The Practice Partner Research Network (PPRNet) is a network of primary care practices that all use the same Electronic Health Record-Practice Partner (Physicians Microsystems, Inc, Seattle, Wash). Their approach to research, QI, and collaborative learning has 3 major components: practice reports, site visits, and network meetings. Practice reports show historical and current practice-level adherence with clinical guidelines, as well as with PPRNet and national benchmarks. Site visits by 
a physician with expertise in the practice guidelines, practice-based QI, and the Practice Partner Electronic Health Record occur 2 to 4 times annually. These visits provide an opportunity for academic detailing, assistance with QI efforts, and additional Electronic Health Record training. At annual network meetings, clinicians and staff members share best practice approaches for improvement. Sites can also request and receive between-visit e-mail and telephone support from the project team.

Lessons learned in PPRNet can be disseminated by Physicians Microsystems, Inc, to its other users and incorporated into software updates and improvements in training. The company can also point to its affiliation with the Medical University of South Carolina and PPRNet as evidence of innovation and stability, and to potential membership in PPRNet as an advantage of purchasing their software.

\section{Recommendations}

\section{For Network Directors}

- Be sure that the organization of your network is aligned with its mission. Consider the advantages of a small, highly motivated membership in terms of efficiency and effectiveness, but also its limitations in regard to the generalizability and dissemination of project findings.

- Clarify the purpose of your network in such a way that potential stakeholders and funding agencies can understand how they can collaborate and contribute.

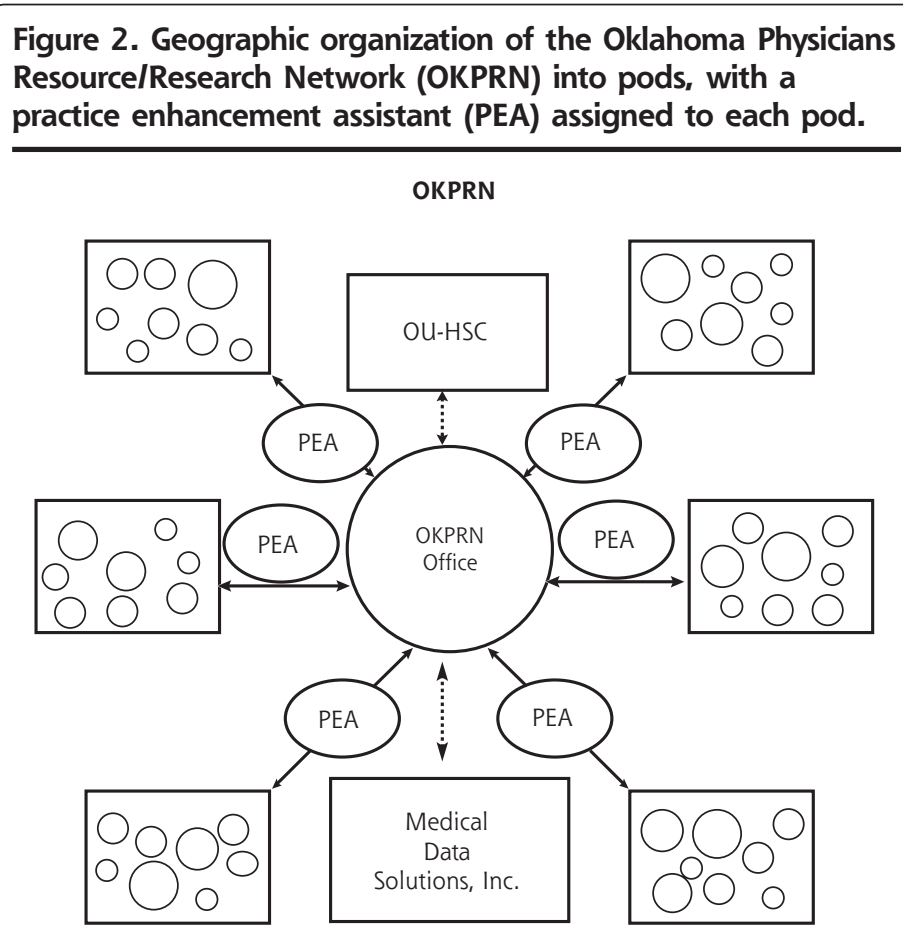

OU-HSC = Oklahoma University Health Sciences Center.

\section{PBRNS AS LEARNING COMMUNITIES}

The assumption that research flows in only one direction leads to the belief that all knowledge flows in that same direction. As a result, the knowledge acquired by primary care practitioners while doing their jobs has been discounted and, therefore, has largely gone untapped. Most clinicians never publish papers or give presentations at meetings. Within the QI community, there is a recognition that true learning builds from microsystems to organizations. ${ }^{67-69}$ It is at the front line, where patients, clinicians, and information meet, that learning begins. A leader or organization that attempts to improve quality of care from the top down may have some effect, but it is unlikely to be large or sustainable.

PBRNs are learning to mine the wisdom of practitioners to more effectively and efficiently address common clinical and administrative challenges. The methods used include interviews, surveys, and direct observation. Knowledge exchange also occurs on listservs, at project development meetings and network convocations, through newsletters, and via practice facilitators. Newer methods, such as best practices research, allow researchers to systematically identify, characterize, and disseminate new knowledge and applications derived from frontline clinical and administrative microsystems. ${ }^{70}$

DuFour and Eaker and others ${ }^{71-76}$ state that there are 6 characteristics of a professional learning community:

(1) a shared mission and values, (2) collective inquiry, (3) collaborative teams, (4) an action orientation including experimentation, (5) continuous improvement, and (6) a results orientation. As PBRNs evolve, they appear to be incorporating many of these principles.

\section{Example: The Oklahoma Physicians Resource/Research Network}

OKPRN is organized geographically into pods of practices, and each pod has a practice enhancement assistant (Figure 2). These assistants identify and exchange ideas, methods, questions, and challenges between practices within their pod and, through the central office, to the rest of the network; facilitate $\mathrm{QI}$; and assist practices to participate in network-wide projects. Practice enhancement assistants also help practices apply the information gained from network research projects. In addition, collaborative learning occurs via an active member listserv, a Web site, a biennial newsletter, practice visits by the network director, and 2 convocations per year. 
Researchers affiliated with this network have developed a method called best practices research to answer questions of the form, "What is the best way to do ?" This method involves dividing the process being studied into its individual steps or components, establishing criteria for what constitutes best practice for each step, identifying exemplars from the network for each step using practice audits, combining the methods used by exemplars into a combined best method, and then testing the combined method in other network practices. The advantages of tapping into the wisdom of practitioners in this way include efficiency (an important requirement in practice-based research), feasibility, and the fact that solutions, or at least their components, have already been field-tested. Examples of processes studied to date include management of laboratory test results, ${ }^{77}$ management of prescription refills, care of diabetic patients, and delivery of adult immunizations.

\section{Recommendations}

\section{For Network Directors}

- Build into your network as many ways as possible for network members to learn from each other

- Consider developing ways to systematically capture and disseminate good ideas and successful approaches.

- Read about professional learning communities and learning organizations, and incorporate the concepts into your network.

\section{VALUE AND SUSTAINABILITY OF PBRNS}

If an organization produces sufficient value for its members, the members will make sure that the organization survives. It is therefore critical that PBRNs understand what their members value. Likewise, if an organization produces sufficient value for others, they will support it. Financial support can almost always be found to do things that are worthwhile. It is therefore important to include potential beneficiaries in organizational decision making. PBRN advisory boards often include clinicians, office staff, patients, academicians, public health officials, and representatives of professional associations, QI organizations, insurance carriers, and private industry. Funding sources include both grants and contracts from a variety of sources. Some PBRNs are also considering membership dues and charitable contributions programs.

PBRNs are extremely frugal and efficient organizations, but they do require predictable financial support for infrastructure and additional project-specific revenues. Most have depended heavily on in-kind support from academic medical centers. Faculty and staff resources can be devoted to PBRN activities because these activities lead to grants, contracts, publications, presentations, tenure, and promotion for faculty and various intangible benefits to the academic medical center (eg, community goodwill, patient referrals, legislative support). This relationship can, however, result in an overemphasis on traditional academic values (eg, publications, grants), leading back to research as the goal and an underappreciation of the values and needs of PBRN members and other critical partners.

Academic faculty and staff are critical components of effective networks. Busy clinicians have little time and insufficient skills to write grant applications, design studies, and direct most projects, but academicians must learn to become contributors to a collaborative effort rather than the sole drivers of the effort. Principal investigators must be willing to subjugate their own research agendas to the needs and interests of the group. Successful networks have been able to find researchers willing to do this, but in many institutions, it may be necessary to train researchers and administrators.

\section{Recommendations}

\section{For Network Directors}

- Identify researchers who are more interested in improving primary care practice than they are in studying a single topic area, or identify a large enough cadre of researchers to cover the methodologic needs of the network.

- Develop training programs (eg, workshops, seminars, mini-fellowships) wherein researchers interested in working with your network can be trained.

- Identify organizations and funding agencies that share your network's mission and goals. Include them on your advisory board, and keep them apprised of your activities and accomplishments. Encourage network members to serve on these organizations' and agencies' advisory boards as well.

- Consider instituting membership dues as a way to generate funds for infrastructure and to increase commitment to the network.

- Approach your academic medical center or hospital's development office for help in identifying potential charitable contributions. Point out to the medical center the value of a PBRN including, but not limited to, community goodwill, subspecialty referrals, and grants and contracts.

\section{For PBRN Clinician Members}

- Begin talking about the network with your patients. Ask some of them about their interest in making a financial contribution.

- Approach retired colleagues and others who might have an interest in network activities. 


\section{CONCLUSIONS}

Primary care PBRNs appear to be evolving into collaborative learning organizations that use techniques borrowed from QI and research, and developing new methods of their own. These networks are bridging traditional gaps between town and gown, private and public, and research and QI. Technologic advances have increased the ease of communication, collaboration, and data sharing, which may substantially alter existing models of research and practice. Barriers that have traditionally separated the researcher from the practitioner are disappearing. Whether PBRNs will become the engines of innovation and improvement in the delivery of primary health care will depend on the ability and the commitment of the critical partners and stakeholders to work together toward worthwhile goals.

To read or post commentaries in response to this article, see it online at http://www.annfammed.org/cgi/content/full/3/Suppl_1/S12.

Key words: Primary health care; quality improvement; practice-based research network; practice-based research; quality of health care

Submitted May 26, 2004; submitted, revised, January 12, 2005; accepted, January 17, 2005.

Acknowledgments: The authors wish to thank Lavonne Glover for her assistance in preparation of this manuscript for publication.

\section{References}

1. Webster's New Dictionary and Thesaurus of the English Language. Danbury, Conn: Lexicon Publications, Inc; 1993.

2. American College of Medical Quality, Professional Policies, Index. Available at: http://www.acmq.org. Accessed October 19, 2004

3. Bellin E, Dubler NN. The quality improvement-research divide and the need for external oversight. Am J Public Health. 2001;91:1512-1517.

4. McNelly JA. Taking the mystery out of research: comparative analysis of research, quality improvement, and quality assurance. Orthop Nurs. 1997; 17:68.

5. Demakis JG, McQueen L, Kizer KW, Feussner JR. Quality Enhancement Research Initiative (QUERI): a collaboration between research and clinical practice. Med Care. 2000;38(6 Suppl 1):117-125.

6. Reinhardt AC, Ray LN. Differentiating quality improvement from research. Appl Nurs Res. 2003;16:2-8.

7. Morrison E, Mobley D, Farley B. Research and continuous improvement: the merging of two entities. Hosp Health Serv Adm. 1996;41:359-372.

8. Perrin EB. Some thoughts on outcomes research, quality improvement, and performance measurement. Med Care. 2002;40(6 Suppl):III89-III91.

9. McQueen L, Mittman BS, Demakis JG. Overview of the Veterans Health Administration (VHA) Quality Enhancement Research Initiative (QUERI). J Am Med Inform Assoc. 2004;22:339-343.

10. Speroff T, O'Connor GT. Study designs for PDSA quality improvement research. Qual Manag Health Care. 2004;13:17-32.

11. Lynn J. When does quality improvement count as research? Human subject protection and theories of knowledge. Qual Saf Health Care. 2004; 13:67-70.

12. Casarett D, Karlawish JH, Sugarman J. Determining when quality improvement initiatives should be considered research: proposed criteria and potential implication. JAMA. 2000;283:2275-2280.
13. Doezema D, Hauswald M. Quality improvement or research: a distinction without a difference. IRB. 2002;24:9-12.

14. Byers JF, Beaudin CL. The relationship between continuous quality improvement and research. J Healthc Qual. 2002;24:4-8; quiz 8, 48.

15. Martin PA. Is it research? Appl Nurs Res. 1995;8:199-201.

16. Meehan TP, Tate JP, Holmboe ES, et al. A collaborative initiative to improve the care of elderly Medicare patients with hypertension. Am J Med Qual. 2004;193:103-111.

17. Schade CP, Cochran BF, Stephens MK. Using statewide audit and feedback to improve hospital care in Virginia. Jt Comm J Qual Saf. 2004;30:143-151

18. Ballard DJ, Nicewander D, Skinner C. Health care provider quality improvement organization Medicare data-sharing: a diabetes quality improvement initiative. Proc AMIA Symp. 2002:22-25.

19. Havranek EP, Masoudi FA, Ralston DL, Susman NJ, Krumholz HM, Taylor JP. Future challenges in quality improvement in heart failure. Congest Heart Fail. 2002;8:342-345.

20. Florida QIO uses federal data to strike up a conversation with longterm care facilities. Data Strateg Benchmarks. 2002;6:92-95.

21. Kilo CM. A framework for collaborative improvement: lessons from the Institute for Healthcare Improvement's Breakthrough Series. Qual Manag Health Care. 1998;6:1-13.

22. Ovretveit J, Bate $P$, Cleary $P$, et al. Quality collaboratives: lessons from research. Qual Saf Health Care. 2002;11:345-351.

23. Bate S, Robert G, McLeod H. Report on the "Breakthrough" collaborative approach to quality and service improvement within four regions of the NHS: a research based investigation of the orthopaedic services collaborative within the Eastern, South $\&$ West, South East, and Trent regions. Birmingham, UK: Health Services Management Centre, University of Birmingham, 2001. Research report No. 42.

24. Wilson T, Plsek P, Berwick D, et al. Learning From Around the World: Experiences and Thoughts of Collaborative Improvement From Seven Countries. Boston, Mass: Institute for Healthcare Improvement; 2001.

25. Wilson T, Berwick DM, Cleary PD. What do collaborative improvement projects do? Experience from seven countries. Jt Comm J Qual Saf. 2003;29:85-93.

26. Ovretveit J. How to run an effective improvement collaborative. Int $J$ Health Care Qual Assur. 2002;15:192-196.

27. Kilo CM. Improving care through collaboration. Pediatrics. 1999; 103(Suppl E):384-393.

28. Plsek PE. Collaborating across organizational boundaries to improve the quality of care. Am J Infect Control. 1997;25:85-95.

29. Flamm B, Berwick D, Kabcenell A. Reducing cesarean section rates safely: lessons from a "breakthrough series" collaborative. Birth. 1998;25:117-124

30. Leape LL, Kabcenell Al, Gandhi TK, et al. Reducing adverse drug events: lessons from a breakthrough series collaborative. Jt Comm J Qual Improv. 2000;26:321-331.

31. Chin MH, Cook S, Drum ML, et al. Improving diabetes care in Midwest community health centers with the health disparities collaborative. Diabetes Care. 2004;27:2-8.

32. Horbar J, Rogowski J, Plsek P, et al. Collaborative quality improvement for neonatal intensive care. Pediatrics. 2001;107:14-22.

33. Fernald DH, Pace WD, Harris DM, West DR, Main DS, Westfall JM. Event reporting to a primary care patient safety reporting system: a report from the ASIPS Collaborative. Ann Fam Med. 2004;2:327-332.

34. Narayan KM, Benjamin E, Gregg EW, Norris SL, Engelgau MM. Diabetes translation research: where are we and where do we want to be? Ann Intern Med. 2004;140:958-963.

35. Feifer C, Fifield J, Ornstein S, et al. From research to daily clinical practice: what are the challenges in "translation"? Jt Comm J Qual Saf. 2004;30:235-245

36. Majumdar SR, McAlister FA, Furberg CD. From knowledge to practice in chronic cardiovascular disease: a long and winding road. J Am Coll Cardiol. 2004;43:1738-1742. 
37. Glasgow RE, Klesges LM, Dzewaltowski DA, Bull SS, Estabrooks PA. The future of health behavior change research: what is needed to improve translation of research into health promotion practice? Ann Behav Med. 2004;27:3-12

38. Lenfant C. Shattuck lecture-clinical research to clinical practicelost in translation? N Engl J Med. 2003;349:868-874.

39. Glasgow RE, Lichtenstein E, Marcus AC. Why don't we see more translation of health promotion research into practice? Rethinking the efficacyto-effectiveness transition. Am J Public Health. 2003;93:1261-1267.

40. Davis D, Evans M, Jadad A, et al. The case for knowledge translation: shortening the journey from evidence to effect. BMJ. 2003;327:33-35

41. Davis DA, Taylor-Vaisey A. Translating guidelines into practice: a systematic review of theoretic, concepts, practical experience and research evidence in the adoption of clinical practice guidelines. CMAJ. 1997; 157:408-416.

42. Freemantle N, Harvey EL, Wolf F, Grimshaw JM, Grilli R, Bero LA. Printed educational materials: effects on professional practice and health care outcomes. Cochrane Database Syst Rev. 2000;(2): CD000172.

43. Davis D, O'Brien MA, Freemantle N, Wolf FM, Mazmanian P, TaylorVaisey A. Impact of formal continuing medical education: do conferences, workshops, rounds, and other traditional continuing education activities change physician behavior or health care outcomes? JAMA. 1999;282:867-874.

44. Zwarenstein M, Reeves S, Barr H, Hammick M, Koppel I, Atkins J. Interprofessional education: effects on professional practice and health care outcomes. Cochrane Database Syst Rev. 2001;(1): CD002213.

45. Oxman AD, Thomson MA, Davis DA, Haynes RB. No magic bullets: a systematic review of 102 trials of interventions to improve professional practice. CMAJ. 1995;153:1423-1431.

46. Davis DA, Thomson MA, Oxman AD, Haynes RB. Changing physician performance: a systematic review of the effectiveness of continuing medical education strategies. JAMA. 1995;274:700-705.

47. Davis D. Does CME work? An analysis of the effect of educational activities on physician performance or health care outcomes. Int J Psychiatry Med. 1998;28:21-39.

48. Tu K, Davis D. Can we alter physician behavior by educational methods? Lessons learned from studies of the management and follow-up of hypertension. J Contin Educ Health Prof. 2002;22:11-22.

49. Sohn W, Ismail Al, Tellez M. efficacy of educational interventions targeting primary care providers' practice behaviors: an overview of published systematic reviews. J Public Health Dent. 2004;64:164-172.

50. Thomson O'Brien MA, Freemantle N, Oxman AD, Wolf F, Davis DA, Herrin J. Continuing education meetings and workshops: effects on professional practice and health care outcomes. Cochrane Database Syst Rev. 2001;(2):CD003030.

51. Balas EA, Boren SA. Managing clinical knowledge for health care improvement. In: Yearbook of Medical Informatics 2000: Patient-Centered Systems. Stuttgart, Germany: Schattauer; 2000:65-70.

52. Crabtree BF. Primary care practices are full of surprises! Health Care Manage Rev. 2003;28:279-283; discussion 289-290.

53. Miller WL, McDaniel RR Jr, Crabtree BF, Stange KC. Practice jazz: understanding variation in family practices using complexity science. J Fam Pract. 2001;50:872-878.

54. Cohen D, McDaniel RR Jr, Crabtree BF, et al. A practice change model for quality improvement in primary care practice. $J$ Healthc Manag. 2004;49:155-168; discussion 169-170.

55. Bradley EH, Webster TR, Baker D, et al. Translating research into practice: speeding the adoption of innovative health care programs. Commonwealth Fund Publications. Available at: http://www.cmwf. org. Accessed October 19, 2004.
56. NIH Roadmap Initiatives. Available at: http://nihroadmap.nih.gov/ initiatives.asp. Accessed September 22, 2004.

57. Overview of the NIH Roadmap. Available at: http://nihroadmap.nih. gov/overview.asp. Accessed September 22, 2004.

58. Agency for Health Care Policy and Research: AHCPR Strategic Plan. Available at: http://www.ahrq.gov/about/stratpln.htm. Accessed September 22, 2004.

59. Adams A, Miller-Korth N, Brown D. Learning to work together: developing academic and community research partnerships. WMJ 2004; 103:15-19.

60. Ammerman A, Corbie-Smith G, St George DM, Washington $C$ Weathers B, Jackson-Christian B. Research expectations among African American church leaders in the PRAISE! Project: a randomized trial guided by community-based participatory research. Am J Public Health. 2003;93:720-727.

61. Marincowitz GJ. How to use participatory action research in primary care. Fam Pract. 2003;20:595-600.

62. O'Toole TP, Aaron KF, Chin MH, Horowitz C, Tyson F. Communitybased participatory research: opportunities, challenges and the need for a common language. J Gen Intern Med. 2003;18:592-594.

63. Gosin MN, Dustman PA, Drapeau AE, Harthun ML. Participatory action research: creating an effective prevention curriculum for adolescents in the southwestern US. Health Educ Res. 2003;18:363-379.

64. Giachello AL, Arrom JO, Davis M, et al, for the Chicago Southeast Diabetes Community Action Coalition. Reducing diabetes health disparities through community-based participatory action research: the Chicago Southeast Diabetes Community Action Coalition. Public Health Rep. 2003;118:309-323.

65. North American Primary Care Research Group. NAPCRG Policy Statement, November 6, 1998. Available at: http://www.napcrg.org/ rrpolicy.html. Accessed October 19, 2004.

66. Nelson $E$, Conger $B$, Douglass $R$, et al. Functional health status levels of primary care patients. JAMA. 1983;249:3331-3338.

67. Using clinical microsystems to improve quality at all levels. Qual Lett Healthc Lead. 2003;15:2-11, 1.

68. Mills PD, Weeks WB, Surrot-Kimberly BC. A multihospital safety improvement effort and the dissemination of new knowledge. Jt Comm J Qual Saf. 2003;29:124-133.

69. Lurie JD, Merrens EJ, Lee J, Splaine ME. An approach to hospital quality improvement. Med Clin North Am. 2002;86:825-845.

70. Mold JW, Gregory ME. Best practices research. Fam Med. 2003;35:131-134

71. DuFour R, Eaker R. Professional learning communities at work: best practices for enhancing student achievement. Bloomington, Ind: National Educational Service; 1998. Available at: http://www.nesonline.com. Accessed October 19, 2004.

72. Senge PM, Kleiner A, Roberts C, Ross RB, Smith BJ, Brierley N. The Fifth Discipline Fieldbook: Strategies and Tools for Building a Learning Organization. New York, NY: Doubleday; 1994.

73. Senge P. The Fifth Discipline: The Art and Practice of the Learning Organization. New York, NY: Currency Doubleday; 1990.

74. Hord SM. Professional Learning Communities: Communities of Continuous Inquiry and Improvement. Austin, Tex: Southwest Educational Development Laboratory; 1997. Available at: http://www.sedl.org/ siss/plc/plc.html.

75. Hord SM. Professional learning communities: what are they and why are they important? 1997. Available at: http://www.sedl.org/ change/issues/issues61.html.

76. Malhotra Y. Organizational learning and learning organizations: an overview. Available at: http://www.kmbook.com/orglrng.htm. Accessed October 19, 2004.

77. Mold JW, Cacy ES, Dalbir EK. Management of laboratory test results in family practice: and OKPRN study. J Fam Pract. 2000;49:709-715. 